\title{
Rasburicase in the management of tumor lysis: an evidence-based review of its place in therapy
}

This article was published in the following Dove Press journal:

Core Evidence

13 January 2015

Number of times this article has been viewed

\author{
Jennifer Dinnel' \\ Bonny L Moore' \\ Brent M Skiver' \\ Prithviraj Bose ${ }^{1,2}$ \\ 'Department of Internal Medicine, \\ Virginia Commonwealth University, \\ ${ }^{2}$ VCU Massey Cancer Center, \\ Richmond, VA, USA
}

Correspondence: Prithviraj Bose

I20I East Marshall Street,

MMEC I I th Floor, Room 213 ,

Richmond, VA 23298, USA

Tel +l 8048289723

Fax + I 8046285920

Email pbose@mcvh-vcu.edu
Abstract: Tumor lysis syndrome (TLS) is a potentially life-threatening complication of cancer therapy characterized by two or more of the following laboratory abnormalities: hyperuricemia, hyperkalemia, hypocalcemia, and hyperphosphatemia, with resultant end-organ damage, eg, renal failure, seizures, or cardiac arrhythmias. High-risk patients include those with highly proliferative cancers and/or large tumor burdens, particularly in the setting of highly effective chemotherapy, among other risk factors. Before 2002, antihyperuricemic drug therapy was limited to allopurinol, a xanthine oxidase inhibitor. Rasburicase, a recombinant urate oxidase, was approved by the US Food and Drug Administration for children in 2002 and adults in 2009 , ushering in a new era in TLS therapy. We attempted to critically appraise the available evidence supporting the perceived benefits of rasburicase in the management of TLS. A Medline search yielded 98 relevant articles, including 26 retrospective and 22 prospective studies of rasburicase for the treatment of TLS, which were then evaluated to determine the best available evidence for the effectiveness of rasburicase in terms of disease-oriented, patient-oriented, and economic outcomes. Rasburicase is now a standard of care for patients at high risk of TLS despite continuing debate on the correlation between its profound and rapid lowering of plasma uric acid levels with hard patient outcomes, eg, need for renal replacement therapy and mortality. Rasburicase is dramatically effective in lowering plasma uric acid levels. The mortality and cost-effectiveness benefits of this expensive drug remain to be conclusively proven, and well designed, randomized controlled trials are needed to answer these fundamentally important questions.

Keywords: rasburicase, hyperuricemia, uric acid, urate oxidase, tumor lysis syndrome, evidence

Clinical impact summary for rasburicase in tumor lysis syndrome

\begin{tabular}{|c|c|c|}
\hline $\begin{array}{l}\text { Outcome } \\
\text { measure }\end{array}$ & Evidence & Implications \\
\hline \multicolumn{3}{|c|}{ Disease-oriented outcomes } \\
\hline $\begin{array}{l}\text { Reduction of } \\
\text { PUA levels }\end{array}$ & $\begin{array}{l}\text { Level I, with two systematic reviews } \\
\text { and two RCTs }\end{array}$ & $\begin{array}{l}\text { Reliable, rapid, and effective } \\
\text { reduction of PUA, which should in } \\
\text { theory prevent or mitigate adverse } \\
\text { TLS sequelae, eg, AKI }\end{array}$ \\
\hline $\begin{array}{l}\text { Reduction of } \\
\text { LTLS incidence }\end{array}$ & Level 2 with one RCT & $\begin{array}{l}\text { Prevention of LTLS, a potentially life- } \\
\text { threatening condition which, in turn, } \\
\text { should lead to prevention of CTLS } \\
\text { Additionally, this may allow for earlier } \\
\text { initiation and more effective dosing of } \\
\text { chemotherapy }\end{array}$ \\
\hline
\end{tabular}

(Continued) 


\begin{tabular}{|c|c|c|}
\hline \multicolumn{3}{|l|}{ (Continued) } \\
\hline $\begin{array}{l}\text { Outcome } \\
\text { measure }\end{array}$ & Evidence & Implications \\
\hline \multicolumn{3}{|c|}{ Patient-oriented outcomes } \\
\hline $\begin{array}{l}\text { Prevention } \\
\text { of CTLS/AKI/ } \\
\text { need for RRT }\end{array}$ & $\begin{array}{l}\text { Level } 3 \text { from pooled results of CCTs in the } \\
\text { pediatric population (some of these studies } \\
\text { used Uricozyme }{ }^{\circledR} \text {, a nonrecombinant urate } \\
\text { oxidase, rather than rasburicase) and } \\
\text { multiple observational studies and cross- } \\
\text { trial comparisons }\end{array}$ & $\begin{array}{l}\text { May represent an effective and safe } \\
\text { alternative to RRT and all of the short/ } \\
\text { long-term sequelae (physical, emotional, } \\
\text { financial) associated with RRT. May also } \\
\text { allow for earlier initiation and more } \\
\text { effective dosing of chemotherapy }\end{array}$ \\
\hline $\begin{array}{l}\text { Reduction in } \\
\text { ICU admissions } \\
\text { and hospital/ } \\
\text { ICU LOS }\end{array}$ & $\begin{array}{l}\text { Level } 3 \text { (only ICU LOS in the pediatric } \\
\text { population) from matched case control } \\
\text { studies with potential bias }\end{array}$ & $\begin{array}{l}\text { May have some of the same physical, } \\
\text { emotional, and financial benefits that } \\
\text { are associated with decreased ICU } \\
\text { stay and duration of hospitalization. }\end{array}$ \\
\hline Mortality & $\begin{array}{l}\text { Level } 3 \text { from pooled results of CCTs in the } \\
\text { pediatric population (some of these studies } \\
\text { used Uricozyme }{ }^{\circledR} \text {, a nonrecombinant urate } \\
\text { oxidase, rather than rasburicase) }\end{array}$ & $\begin{array}{l}\text { Only TLS, not overall, mortality } \\
\text { benefit }\end{array}$ \\
\hline \multicolumn{3}{|c|}{ Economic outcomes } \\
\hline $\begin{array}{l}\text { Cost- } \\
\text { effectiveness }\end{array}$ & Level 5 based on descriptive studies & $\begin{array}{l}\text { Unclear overall health care cost } \\
\text { benefit }\end{array}$ \\
\hline $\begin{array}{l}\text { Dose } \\
\text { reduction }\end{array}$ & $\begin{array}{l}\text { Level I with meta-analysis of dose } \\
\text { reduction studies showing non-inferior } \\
\text { efficacy }\end{array}$ & $\begin{array}{l}\text { Uses of lower doses than FDA- } \\
\text { approved makes rasburicase more } \\
\text { cost-effective }\end{array}$ \\
\hline
\end{tabular}

\section{Introduction}

Tumor lysis syndrome (TLS) is a potentially devastating complication of cancer treatment triggered by massive cell lysis that overwhelms normal homeostatic mechanisms (although it can occasionally occur spontaneously). Laboratory TLS (LTLS) is defined by the simultaneous occurrence (within the same 24-hour period) of two or more of four classic metabolic derangements (hyperkalemia, hyperphosphatemia, hyperuricemia, hypocalcemia, ${ }^{1}$ as shown in Table 1) either 3 days before or 7 days after initiation of cytotoxic chemotherapy. ${ }^{2}$ Clinical TLS (CTLS) is defined as LTLS plus one or more of the following: increased serum creatinine level, cardiac arrhythmias, seizures, or death. ${ }^{2}$

Patients at highest risk for TLS are those having chemosensitive malignancy with a high proliferation rate and/or a large tumor burden. Clinically, pre-existing kidney disease, elevated pretreatment uric acid, and volume depletion also predict a higher risk for TLS. If undiagnosed or diagnosed

Table I Cairo-Bishop criteria for laboratory tumor lysis syndrome

\begin{tabular}{|c|c|c|}
\hline $\begin{array}{l}\text { Metabolic } \\
\text { abnormality }\end{array}$ & $\begin{array}{l}\text { Criteria for classification of laboratory tumor } \\
\text { lysis syndrome }\end{array}$ & $\begin{array}{l}\text { Criteria for classification of clinical tumor } \\
\text { lysis syndrome }\end{array}$ \\
\hline Hyperuricemia & $\begin{array}{l}\text { Uric acid }>8.0 \mathrm{mg} / \mathrm{dL}(475.8 \mu \mathrm{mol} / \text { liter }) \text { in adults or above } \\
\text { the upper limit of the normal range for age in children }\end{array}$ & \\
\hline Hyperphosphatemia & $\begin{array}{l}\text { Phosphorus }>4.5 \mathrm{mg} / \mathrm{dL}(1.5 \mathrm{mmol} / \text { liter }) \text { in adults or } \\
>6.5 \mathrm{mg} / \mathrm{dL}(2.1 \mathrm{mmol} / \text { liter }) \text { in children }\end{array}$ & \\
\hline Hyperkalemia & Potassium $>6.0 \mathrm{mmol} / \mathrm{liter}$ & $\begin{array}{l}\text { Cardiac dysrhythmia or sudden death probably or } \\
\text { definitely caused by hyperkalemia }\end{array}$ \\
\hline Hypocalcemia & $\begin{array}{l}\text { Corrected calcium }<7.0 \mathrm{mg} / \mathrm{dL}(1.75 \mathrm{mmol} / \text { liter }) \text { or } \\
\text { ionized calcium }<\mathrm{I} .12(0.3 \mathrm{mmol} / \text { liter })\end{array}$ & $\begin{array}{l}\text { Cardiac dysrhythmia, sudden death, seizure, neuromuscular } \\
\text { irritability (tetany, paresthesias, muscle twitching, carpopedal } \\
\text { spasm, Trousseau's sign, Chvostek's sign, laryngospasm, or } \\
\text { bronchospasm), hypotension, or heart failure probably or } \\
\text { definitely caused by hypocalcemia }\end{array}$ \\
\hline Acute kidney injury & Not applicable & $\begin{array}{l}\text { Increase in the serum creatinine level of } 0.3 \mathrm{mg} / \mathrm{dL}(26.5 \mu \mathrm{mol} / \mathrm{liter} \text { ) } \\
\text { (or a single value }>1.5 \text { times the upper limit of the } \\
\text { age-appropriate normal range if no baseline creatinine } \\
\text { measurement is available) or the presence of oliguria, } \\
\text { defined as an average urine output of }<0.5 \mathrm{ml} / \mathrm{kg} / \mathrm{hr} \text { for } 6 \mathrm{hr}\end{array}$ \\
\hline
\end{tabular}

Note: From The tumor lysis syndrome, Howard SC, Jones DP, Pui CH,N Engl J Med. 364(19):1844-1854. Copyright @ 20II Massachusetts Medical Society. Reprinted with permission from Massachusetts Medical Society. ${ }^{2}$ 
too late, TLS can lead to death in $20 \%-50 \%$ of cases. ${ }^{3}$ Acute kidney injury (AKI) represents one of the most serious consequences of TLS and predicts mortality. ${ }^{4} \mathrm{AKI}$ in TLS can occur via crystal-dependent and crystal-independent mechanisms, with hyperuricemia playing a central role in both. ${ }^{5}$

Because of the serious morbidity and mortality risks associated with TLS, safe and effective therapies to prevent TLS are needed. ${ }^{2,6}$ Furthermore, the occurrence of TLS can prevent or delay administration of potentially life-saving chemotherapy. ${ }^{7}$ Vigorous hydration and antihyperuricemic therapy remain the cornerstones of management of TLS, while urinary alkalinization is no longer recommended. ${ }^{2,6}$ Whereas allopurinol prevents new uric acid formation by inhibiting xanthine oxidase, rasburicase (Elitek ${ }^{\circledR}$, Sanofi, Bridgewater, NJ, USA) is a recombinant urate oxidase that converts pre-existing uric acid to allantoin, an enzymatic reaction evolutionarily lost in humans. The drug is approved by the US Food and Drug Administration (FDA) for the initial management of plasma uric acid (PUA) levels in both adult and pediatric patients with hematologic or solid organ malignancies who are receiving anticancer therapy expected to cause tumor lysis and subsequent elevation of PUA levels. It is important to note that the drug can continue to work ex vivo and lead to falsely low PUA measurements if the blood is not immediately placed and transported in an ice water bath after collection; correct handling of specimens and measurement of PUA at the 4-hour time point are therefore critical. Although recommended in several consensus guidelines, ${ }^{6,7}$ the use of prophylactic rasburicase in patients at intermediate and high risk for TLS remains controversial. ${ }^{8,9}$ Additionally, the optimal dose and schedule of rasburicase administration continue to evolve. ${ }^{10-15}$ In this paper, we evaluate the available evidence on rasburicase in the management of TLS.

\section{Methods}

Separate searches of the biomedical literature (Medline) were conducted using PubMed to cover the period up to and including August 2014, with the key phrases "tumor lysis syndrome" and "recombinant urate oxidase", and the key words "rasburicase", "hyperuricemia", and "SR29142". A search of the Cochrane database did not recover additional articles beyond those identified in PubMed (Medline). Searches of other databases such as EMBASE were not performed. The searches were limited to English language articles dealing with human subjects. Articles describing TLS and the role of rasburicase in its management in both pediatric and adult patients were included. Twenty-six retrospective and 22 prospective studies along with 50 reviews were found. For patient-oriented and disease-oriented outcomes, all studies examining PUA reduction and/or LTLS/ CTLS prevention, reduction of AKI incidence, need for renal replacement therapy (RRT), intensive care unit (ICU) admission/stay, or mortality were evaluated. For analysis of cost-effectiveness, all studies evaluating cost, including dose reduction studies, were considered. Additionally, studies evaluating the safety of rasburicase were included in our evaluation. All 98 articles were considered for inclusion; however, only those studies providing the highest levels of evidence are discussed in the following subsections. Figure 1 summarizes the search strategy used and the number of articles found in each category.

\section{Disease-oriented outcomes Plasma uric acid reduction}

Although all 98 articles discussed the rapid lowering of uric acid levels by rasburicase, we limited our inclusion criteria to the highest level of evidence, which included two attempted

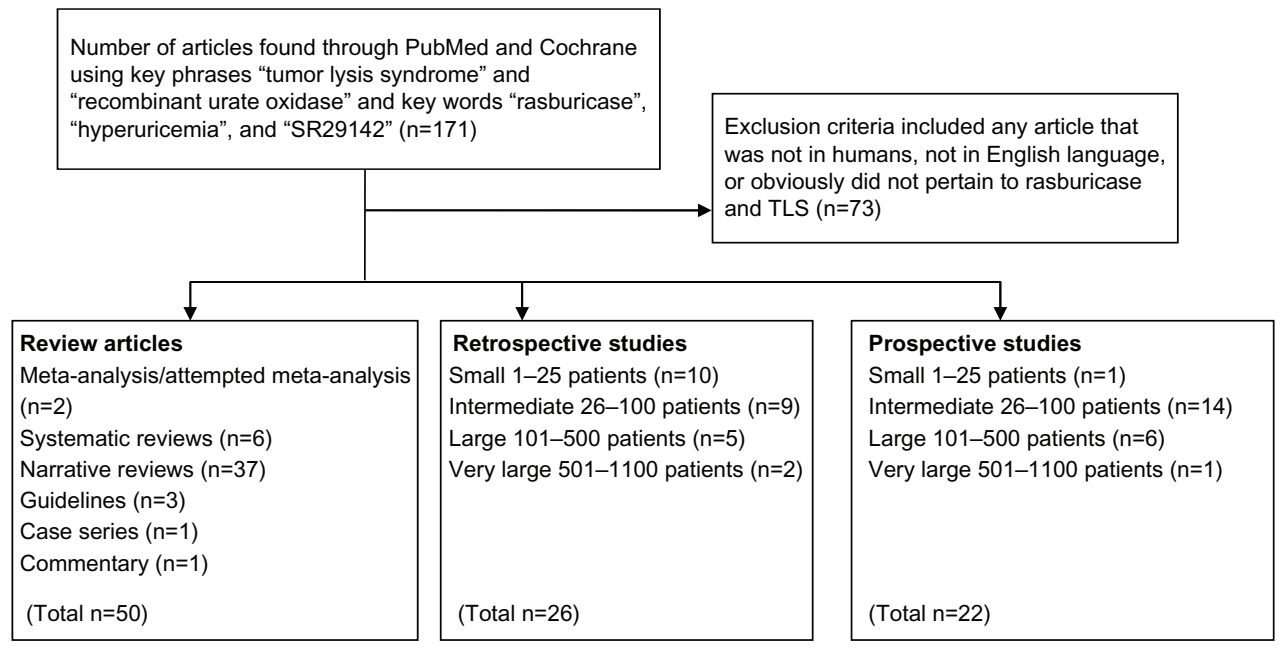

Figure I Search strategy used and number of articles found in each category. 


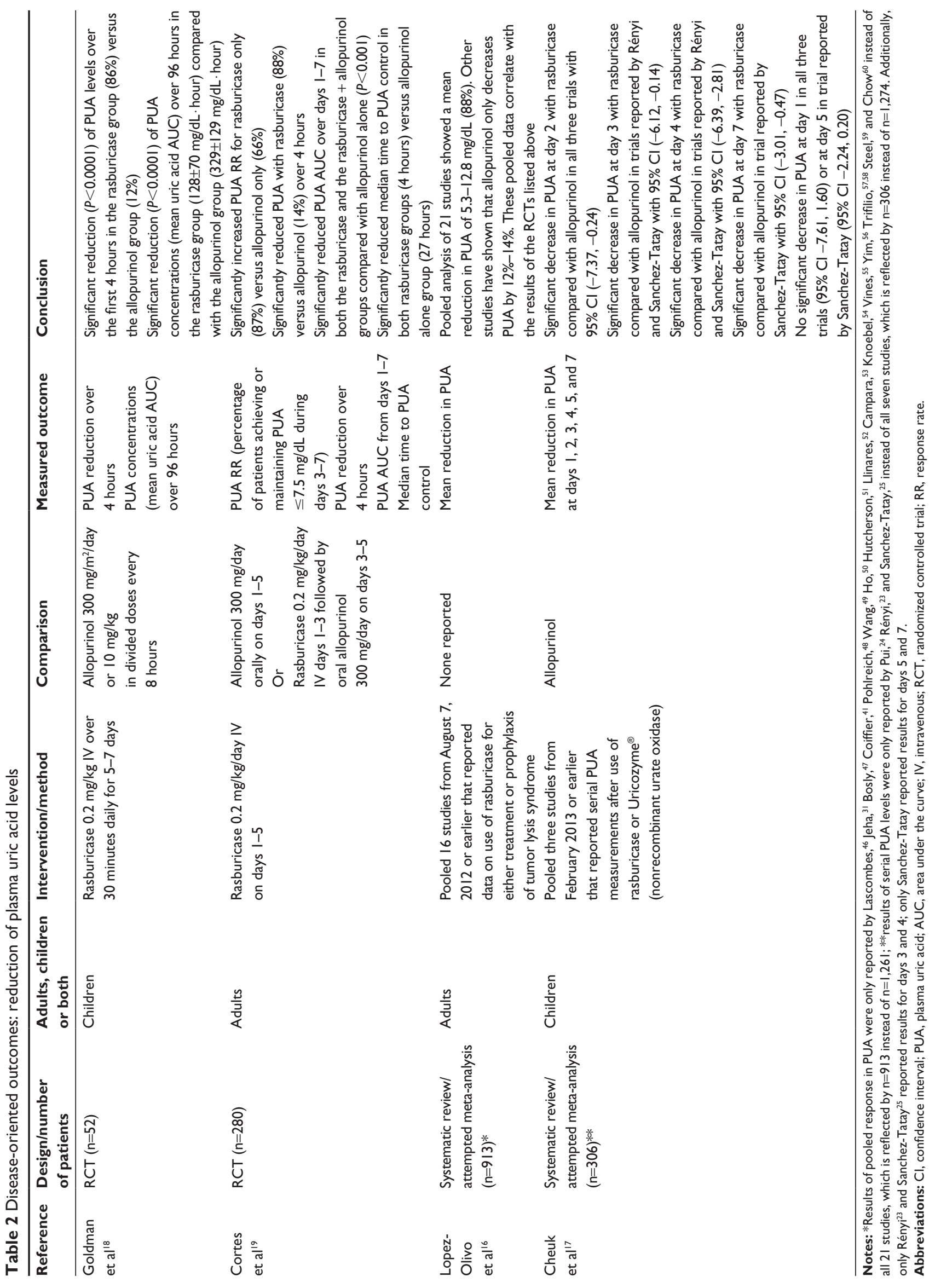


meta-analyses and two randomized controlled trials (RCTs) that discussed lowering PUA levels. ${ }^{16-19}$ All of these studies were consistent in showing a reduction of PUA levels (Table 2).

The notion that rasburicase is superior to allopurinol in lowering PUA is supported by level 1 evidence. Almost all clinical trials clearly demonstrate a rapid reduction in PUA. The two most pivotal trials were reported by Goldman et al in 2001 and Cortes et al in 2010..$^{18,19}$ The former study led to FDA approval of rasburicase for use in children and the latter in adults. Additionally, a meta-analysis was recently attempted after a systematic review of the literature; this again clearly demonstrated the rapid reduction of PUA by rasburicase in adults. ${ }^{16}$ Similar conclusions were reached in a Cochrane database systematic review of the pediatric literature. ${ }^{17}$

\section{Randomized controlled trials}

Goldman et al randomized 52 pediatric patients with leukemia or lymphoma at high risk for TLS to rasburicase or allopurinol for 5-7 days during induction chemotherapy. ${ }^{18}$ There was a dramatic $86 \%$ reduction in PUA levels in the rasburicase group versus only a $12 \%$ reduction $(P<0.0001)$ in the allopurinol group at the 4-hour time point (from the first dose). The primary efficacy endpoint was to compare the area under the serial PUA concentration curves during the first 96 hours of therapy $\left(\mathrm{AUC}_{0-96}\right)$. In an intent-to-treat analysis, the mean uric acid $\mathrm{AUC}_{0-96}$ was $128 \pm 70 \mathrm{mg} / \mathrm{dL} \cdot$ hour in the rasburicase group and $329 \pm 129 \mathrm{mg} / \mathrm{dL} \cdot$ hour in the allopurinol group $(P<0.0001)$, ie, a 2.6-fold reduction in uric acid exposure in the rasburicase group. ${ }^{18}$ It is noteworthy that the results of this pilot study (ie, $86 \%$ and $100 \%$ patients achieving normalization of PUA levels after 24 and 72 hours, respectively) were later confirmed in the multi-institutional, cooperative group setting. ${ }^{20}$

Cortes et al randomly assigned adults with hematologic malignancies at risk for hyperuricemia and TLS to rasburicase $(0.20 \mathrm{mg} / \mathrm{kg} /$ day intravenously on days $1-5, \mathrm{n}=92)$, rasburicase plus allopurinol (rasburicase $0.20 \mathrm{mg} / \mathrm{kg}$ /day intravenously on days 1-3 followed by oral allopurinol $300 \mathrm{mg} /$ day on days $3-5, n=92)$, or allopurinol (300 mg/day orally on days 1 to 5 , $\mathrm{n}=91$ ). The primary efficacy endpoint was the PUA response rate (PUA RR, ie, the percentage of patients achieving or maintaining PUA $\leq 0.5 \mathrm{mg} / \mathrm{dL}$ during days 3-7). The PUA RR was $87 \%$ with rasburicase, $78 \%$ with rasburicase plus allopurinol, and $66 \%$ with allopurinol. ${ }^{19}$ In the comparison between rasburicase and allopurinol, the PUA RRs significantly favored the former in the overall study population, in patients at high risk for TLS, and in those with baseline hyperuricemia. There was an $88 \%$ mean PUA reduction in the rasburicase groups versus only a $14 \%$ mean PUA reduction with allopurinol within the first 4 hours of treatment initiation. Additionally, the PUA AUC from days 1-7 was significantly lower in the rasburicase and rasburicase plus allopurinol groups than in the allopurinol groups $(P<0.001) .{ }^{19}$ Median time to PUA control in hyperuricemic patients was 4 hours in each of the rasburicase groups compared with 27 hours in the allopurinol only group. ${ }^{19}$ These RCTs provide strong level 2 evidence that rasburicase reduces PUA levels in both children and adults at risk for TLS.

\section{Systematic reviews}

Lopez-Olivo et al systematically reviewed the literature on rasburicase for TLS in the adult population in an attempt to perform a meta-analysis. They included three RCTs, one trial with historical controls, and 17 observational studies. ${ }^{16}$ The pivotal trial discussed above was the only study that directly compared rasburicase with allopurinol, while the other three controlled trials compared different doses/schedules of rasburicase. ${ }^{11,21,22}$ The controlled trials differed in outcomes reported, and a meta-analysis was not performed. However, a pooled analysis of the data from the 21 studies showed a mean reduction in PUA of 5.3-12.8 mg/dL (88\%). These pooled data correlate well with the $86 \%-88 \%$ PUA reduction in the RCTs discussed above. Allopurinol, on the other hand, decreases PUA by only $12 \%-14 \% .^{18,19}$ For $93.4 \%$ of the patients in the systematic review, this decrease placed their uric acid in the normal range. ${ }^{16}$ Since a meta-analysis was not performed by the authors of this systematic review, this is weak level 1 evidence that rasburicase reduces PUA in adults. However, in the pediatric population, the Cochrane database systematic review ${ }^{17}$ found not only a higher frequency of PUA normalization at 4 hours and a significantly lower AUC of PUA at 4 days in the rasburicase group of the $\mathrm{RCT},{ }^{18}$ but also significantly lower PUA levels in patients receiving nonrecombinant urate oxidase or rasburicase at 2, 3, 4, and 7 days based on three controlled clinical trials (CCTs). ${ }^{23-25}$

\section{Patient-oriented outcomes Prevention of LTLS/CTLS and $A K I /$ need for RRT}

Of the 98 articles that were considered for the patient-oriented outcomes of LTLS/CTLS, AKI, and need for RRT, we could only find six articles that actually compared this outcome with the previous standard of care, ie, allopurinol (Table 3). ${ }^{17-20,26,27}$ Two other articles were also included. One was included because it was the only pooled analysis for adults that discussed the incidence of TLS and AKI. ${ }^{16}$ The other was included because it had a similar design (same chemotherapy backbone, similar patient population) to another study that used allopurinol, so provided 


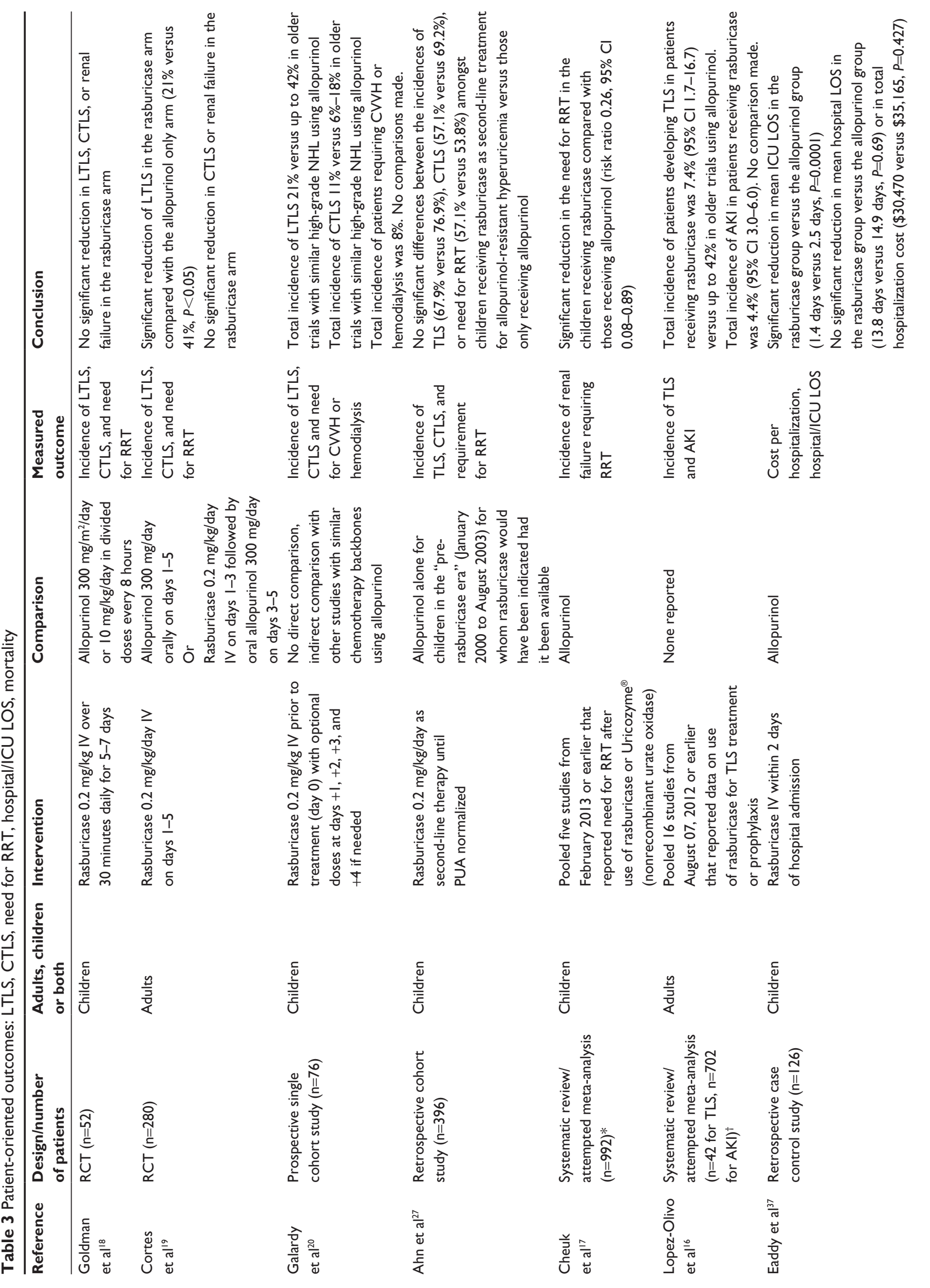




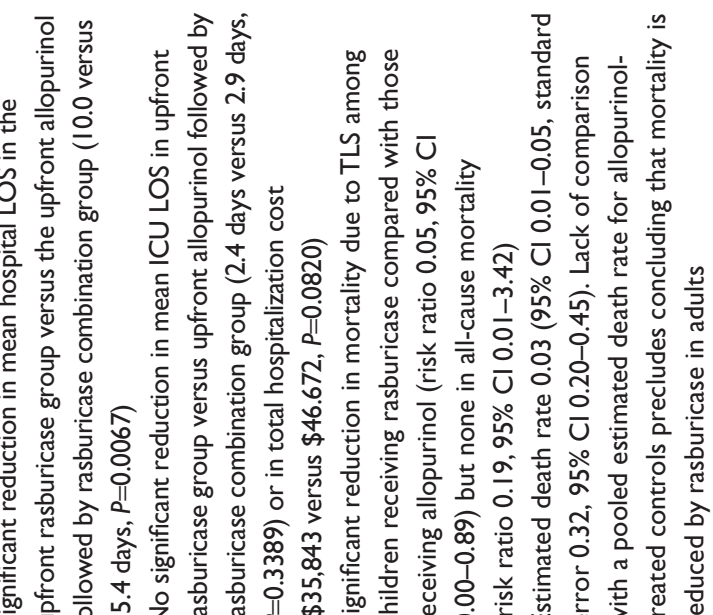

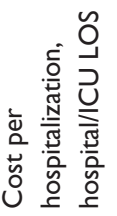
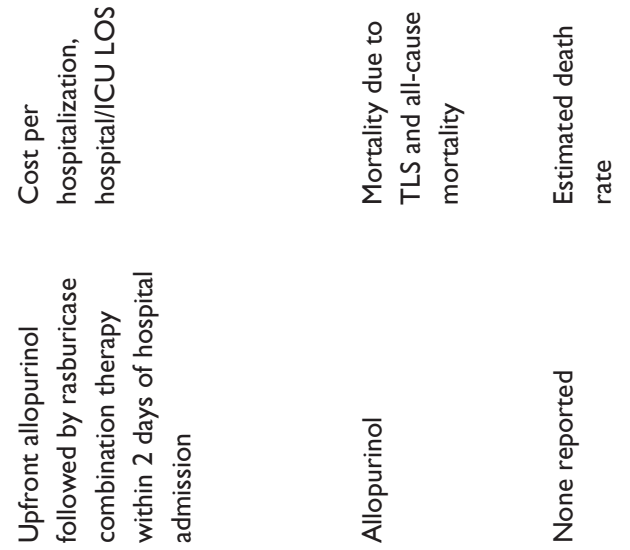

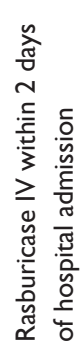

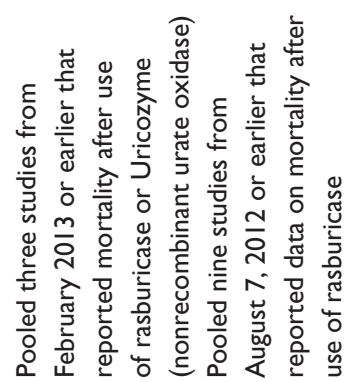

$\frac{\frac{4}{5}}{\frac{7}{4}}$
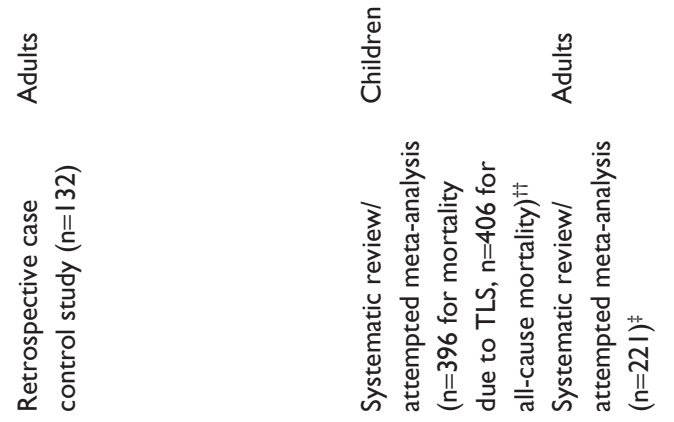

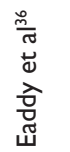
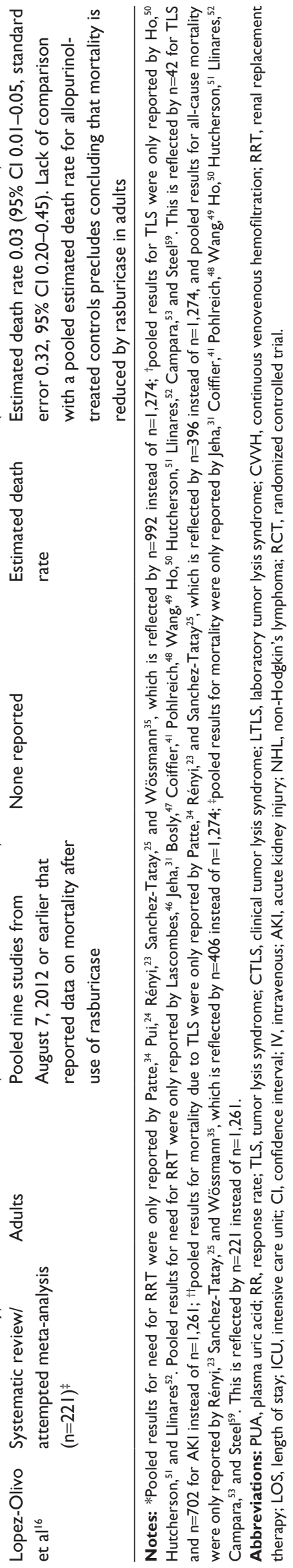
a reasonable comparison of rasburicase with allopurinol in terms of reducing the incidence of LTLS, CTLS, and need for continuous venovenous hemofiltration. ${ }^{25}$ These studies were relatively inconsistent in their results, which was largely due to differences in study design as well as power issues. Additionally, there was a high level of bias in all studies.

Despite some inconsistencies, the studies we found did show that rasburicase is also superior to allopurinol in the prevention of LTLS/CTLS and AKI/need for RRT. Although this statement might seem intuitive, the supportive literature is surprisingly limited, with only level 2 evidence. Uric acid clearly has a significant role in causing AKI in the setting of TLS, ${ }^{5}$ but there are undoubtedly many other factors given that patients whose PUA level normalizes can still have LTLS, CTLS, and/or develop renal failure. ${ }^{20,28}$ Thus, while rasburicase may be superior to allopurinol in the prevention of TLS/renal failure, the benefit is not as profound as originally anticipated. After publication of the pivotal pediatric RCT in 2001 directly comparing rasburicase with allopurinol, ${ }^{18}$ there has only been one other head-to-head prospective study ${ }^{19}$ comparing the two drugs according to our literature search. There have, however, been multiple prospective and retrospective studies that compared the incidence of TLS in the "rasburicase era" to similar patients receiving allopurinol in the "pre-rasburicase era" or between countries where patients in one but not in the other had access to rasburicase. ${ }^{23,28,29}$ These data are somewhat helpful, but have inbuilt selection bias due to the confounding factors inherent in this sort of comparison between different eras and/or health care settings. ${ }^{17,30}$ A Cochrane database systematic review ${ }^{17}$ attempted to address the question of whether rasburicase had an effect on the incidence of LTLS/CTLS and need for RRT in children and Lopez-Olivo et al tried to answer the same question with a systematic review of the adult literature. ${ }^{16}$ Neither was able to draw clear conclusions. ${ }^{16,17}$ Many prospective and retrospective studies on rasburicase assumed superiority over allopurinol; therefore, comparator groups, where present were, for the most part, different doses or durations of administration of rasburicase, which makes a robust comparison of rasburicase with allopurinol in the reduction of LTLS/CTLS and need for RRT difficult.

\section{Randomized controlled trials}

The only two trials that directly compared allopurinol with rasburicase are those that led to the drug's approval for pediatric and adult patients, respectively. ${ }^{18,19}$ Neither trial was designed to measure differences in incidence of LTLS/CTLS or renal failure between the two treatment arms. In the pediatric trial, there was a faster and more pronounced decline in creatinine level in the rasburicase arm, with no one requiring renal replacement. ${ }^{18}$ Even though creatinine levels worsened in the allopurinol group and improved in the rasburicase group over the first 96 hours of therapy, the study sample size was too small to report a significant reduction in the incidence of LTLS/CTLS or renal failure in the rasburicase arm. ${ }^{18}$ In this regard the adult trial had inadequate power too. However, despite small numbers, this trial did note the occurrence of LTLS in only $21 \%$ of patients in the rasburicase group as opposed to $41 \%$ in the allopurinol group, which was a statistically significant reduction $(P<0.05)$; thus reduction of the incidence of LTLS by rasburicase is supported by weak level 2 evidence. ${ }^{19}$ Of note, limited statistical power in this study precluded finding any significant differences in incidence of CTLS or renal failure.

\section{Well designed, nonrandomized trials, single group pre-/post-intervention comparisons, cohort, or matched case control studies}

Several other studies have reported on rasburicase compared with allopurinol with regard to incidence of LTLS/CTLS or renal failure, but these are not RCTs..$^{20,27,29}$ Cairo et al compared different endpoints and outcomes between countries where recombinant urate oxidase was available with those where it was not, and reported a significant improvement in the incidence of TLS, renal insufficiency, and need for dialysis with use of recombinant urate oxidase. ${ }^{29}$ Galardy et al reported a prospective study of rasburicase in newly diagnosed pediatric patients beginning chemotherapy for mature B-cell nonHodgkin's lymphoma (B-NHL) ${ }^{20}$ and Ahn et al attempted to compare outcomes of patients after rasburicase was approved for use by regulatory authorities with those of similar patients in the era before rasburicase became available. ${ }^{27}$ Galardy et al noted a reduction in the incidence of TLS/CTLS with rasburicase in cross-trial comparisons, but theirs was a noncomparative single-arm trial. ${ }^{20} \mathrm{Ahn}$ et al were not able to demonstrate a significant improvement with rasburicase in regard to any outcome measure, but acknowledged significant limitations to their study (see below). ${ }^{27}$

Galardy et al reported on the safety and efficacy of rasburicase in the prevention and treatment of LTLS and CTLS in a prospective study from the Children's Oncology Group involving 85 (76 evaluable) newly diagnosed patients with advanced, mature B-NHL receiving cytoreductive chemotherapy. ${ }^{20}$ In this cohort, the overall incidence of TLS was $32 \%(21 \%$ LTLS $+11 \%$ CTLS). Seventeen 
percent of the patients presented with spontaneous TLS. Direct comparison of the data with those of prior studies was noted to be "... difficult due to differences in definitions, data collection, and reporting" ${ }^{20}$ It was noted that the incidence of CTLS in the study discussed above by Cairo et $\mathrm{al}^{29}$ that used an identical chemotherapy backbone but allopurinol prophylaxis and treatment was $18 \%$, whereas an older analysis of TLS in high-grade NHL, albeit using nonuniform definitions, showed an overall incidence of $42 \%$ with $6 \%$ clinically significant TLS. ${ }^{32}$ Eight percent of patients required assisted renal support in the Children's Oncology Group study, being either continuous venovenous hemofiltration or hemodialysis. ${ }^{20}$

Ahn et al undertook a retrospective study in Korea ${ }^{27}$ where rasburicase was not approved for children until September 2003. Even then, it was only approved as second-line treatment for allopurinol-resistant hyperuricemia, which meant that only 28 children of 68 with TLS (of 396 with acute leukemia or NHL between January 2000 and February 2009) received the drug between September 2003 and February 2009 (ie, the "rasburicase era"). These patients were compared with 13 from the "pre-rasburicase era" (January 2000 to August 2003) for whom rasburicase would have been indicated had it been available, but there were no statistically significant differences in the incidence of TLS or CTLS or requirement for RRT. ${ }^{27}$ Similarly, there were no significant differences in any of these outcomes between the two eras for the entire cohort, or when only considering high-risk patients, such as those with Burkitt's lymphoma. Furthermore, although rasburicase significantly lowered PUA levels in most patients, its availability did not negate the importance of PUA as a risk factor for the development of TLS or CTLS, or requirement of dialysis. This was attributed to the possibility that rasburicase was not given early enough, ie, kidney damage may already have occurred before administration of rasburicase. ${ }^{27}$ Additionally, urine alkalization, which is no longer recommended because of the potential for increased calcium phosphate and xanthine crystallization, ${ }^{2,6}$ was routine. ${ }^{27}$ Although interesting, this study is of limited utility given its small sample size, timing of administration of rasburicase, and routine use of urinary alkalinization, although it suggests that it might be critical to administer rasburicase early to patients at high risk for TLS rather than using it as a rescue therapy for intractable hyperuricemia.

\section{Systematic reviews}

Two large-scale reviews attempted to assess the effects on LTLS/CTLS and AKI/need for RRT; these were a Cochrane database systematic review of the pediatric literature in
$2014^{17}$ and a systematic review by Lopez-Olivo et al of the adult literature in 2013. ${ }^{16}$ Among the seven studies included in the Cochrane review, the only RCT that compared allopurinol with rasburicase was the pivotal trial reported by Goldman et al. ${ }^{18}$ The other six studies included were an RCT that compared different doses of rasburicase ${ }^{33}$ and five CCTs that mostly used historical controls. ${ }^{23-25,34,35}$ Three of the latter did not use rasburicase, but rather Uricozyme ${ }^{\circledR}$ (nonrecombinant urate oxidase). ${ }^{24,34,35}$ All seven were TLS prevention rather than treatment trials. Only one CCT reported the incidence of CTLS and found no significant difference between the group that received Uricozyme and the group that received allopurinol. ${ }^{35}$ None of the seven studies reported the incidence of LTLS. Pooled results of the five $\mathrm{CCTs}^{23-25,34,35}$ showed a significantly lower frequency of renal failure requiring RRT in participants who received urate oxidase compared with those who received allopurinol. This may be considered level 3 evidence in the pediatric population, keeping in mind that some of the studies included used Uricozyme, and others rasburicase. Overall, the authors concluded that it was unclear whether urate oxidase (rasburicase or Uricozyme) reduces CTLS, renal failure, or mortality, noting that none of the included trials were of high methodologic quality. ${ }^{17}$

The other major systematic review was published in 2013 by Lopez-Olivo et al, who looked at the published experience with rasburicase in the adult population in an attempt to perform a meta-analysis. ${ }^{16}$ They included three RCTs, one trial with historical controls, and 17 observational studies involving a total of 1,261 patients. ${ }^{16}$ The pivotal trial reported by Cortes et a $\mathrm{l}^{19}$ was still the only study that directly compared rasburicase with allopurinol while the other three controlled trials compared different doses/schedules of rasburicase. ${ }^{11,21,22}$ No statistically significant differences in development of CTLS were observed in the controlled trials between the rasburicase and control groups. Of 768 patients treated with rasburicase in these studies, 7.4\% developed CTLS despite it, $93.4 \%$ achieved normalization of PUA levels, and 4.4\% developed AKI. No meta-analysis was performed since the controlled trials differed in the outcomes reported. The authors noted that "... evidence currently is lacking in adults to report whether rasburicase use improves clinical outcomes compared with other alternatives". ${ }^{16}$

\section{Reduction in ICU admissions, ICU/ hospital LOS, and health care costs}

Of the 98 articles retrieved by our search, we only found two that compared rasburicase with allopurinol in respect to cost per 
hospitalization, length of stay (LOS), and duration of ICU stay. ${ }^{36,37}$ Both of these studies had a very high level of bias. Additionally, although nearly every article discussed cost, only Annemans et al actually attempted a systematic cost analysis. ${ }^{38,39}$

There is minimal high-quality evidence supporting the contention that use of rasburicase reduces ICU admissions, ICU/ hospital LOS, or health care costs. The two head-to-head RCTs versus allopurinol ${ }^{18,19}$ did not evaluate these outcomes; therefore, there are no RCTs or meta-analyses/systematic reviews on the subject. There were two retrospective studies, both published by Eaddy et al and based on claims data from large hospital databases, which evaluated economic outcomes of the use of rasburicase. ${ }^{36,37}$ The first was a case control study in pediatric patients comparing rasburicase with allopurinol, ${ }^{37}$ and the second was in adults comparing rasburicase with a combination of rasburicase and allopurinol. ${ }^{36}$ Finally, Annemans et al published an "economic evaluation" of rasburicase in the prevention and treatment of hyperuricemia and TLS in hematologic cancer patients $^{39}$ based on incidence and costs of the same derived from a European multicountry chart review ${ }^{38}$ and assumptions regarding the efficacy of rasburicase in reducing hyperuricemia and TLS based on clinical trial data (see below).

\section{Well designed, nonrandomized trials, single group pre-/post-intervention comparisons, cohort, and matched case control studies}

Eaddy et al used claims data from a large hospital database to identify 63 pediatric patients diagnosed with TLS and administered rasburicase within 2 days of hospital admission and matched them with 63 patients who were treated with allopurinol. ${ }^{37}$ They showed that despite higher ICU admission rates on day 1 , rasburicase-treated patients required a significantly shorter duration of critical care compared with allopurinol-treated patients ( 1.4 days versus 2.5 days, $P=0.0001) .{ }^{37}$ However, there was no difference in mean LOS (13.8 days versus 14.9 days, $P=0.69)$ or mean cost per hospitalization $(\$ 30,470$ versus $\$ 35,165, P=0.427) .{ }^{37}$ Thus, this study provides weak level 3 evidence that use of rasburicase in the pediatric population reduces ICU LOS, but not overall LOS or total cost.

Eaddy et al then performed a similar study in adults, but compared 66 patients treated using rasburicase alone with 66 matched patients treated with a combination of rasburicase and allopurinol. ${ }^{36}$ Patients were excluded if they received any kind of RRT. It is not clear if there were differences in the doses or durations of rasburicase administration between the two groups. ${ }^{36}$ Seventeen percent of the combination group only received rasburicase as "rescue". ${ }^{36}$ Patients in the combination therapy group had a shorter mean duration of rasburicase administration than patients in the monotherapy group (2.1 days versus 2.7 days, $P=0.0059$ ). There was a trend towards lower total cost per hospitalization in the rasburicase monotherapy group ( $\$ 35,843$ versus $\$ 46,672, P=0.082$ ). Additionally, patients on rasburicase monotherapy also had a shorter mean overall LOS (10 days versus 15.4 days, $P=0.0067$ ). These data argue against the use of combination therapy, but do not address the fundamental question of which agent is more effective in reducing ICU admissions or hospital/ICU LOS, or which is more cost-effective.

\section{Opinions of respected authorities based on clinical experience, descriptive studies, and reports of expert committees}

Annemans et al estimated the cost of hyperuricemia without TLS to be 672 Euros, that of TLS to be 7,342 Euros and that of TLS requiring dialysis to be 17,706 Euros. ${ }^{38}$ Based on these estimates and an assumed $80 \%-100 \%$ reduction of TLS with rasburicase, they concluded that rasburicase is highly cost-effective for prevention of hyperuricemia and TLS in children and for treatment in adults. ${ }^{39}$ They also noted that the drug was cost-saving in children for treatment of established hyperuricemia/TLS and that in adults, when used as a preventive strategy, the cost-effectiveness depended upon the risk of hyperuricemia/TLS. ${ }^{39}$ Even though there is some evidence that rasburicase reduces TLS more effectively than allopurinol (see above), there is no high-quality evidence that supports an $80 \%-100 \%$ reduction. ${ }^{17}$ Therefore, the evidence that rasburicase is cost-effective compared with allopurinol is still level 5 .

\section{Mortality reduction}

All 48 "primary evidence" studies found in our search reported mortality. To ensure that mortality reduction was due to rasburicase, we only included studies that compared recombinant urate oxidase with allopurinol. This included a systematic review that pooled data from three studies. ${ }^{17} \mathrm{We}$ also included another systematic review that pooled data from nine studies; however, the utility of this was limited because there was no allopurinol comparison. ${ }^{16}$ The risk of bias was high in both systematic reviews.

There is very limited evidence that rasburicase reduces mortality at this time. The randomized pediatric clinical trial versus allopurinol ${ }^{18}$ showed slightly lower mortality in the group that received rasburicase compared with the group that received allopurinol, but this was not statistically significant. In this trial, there was no mortality due to TLS in any patient. ${ }^{18}$ 
In the Cochrane database systematic review of the pediatric literature, ${ }^{17}$ pooled results from three CCTs ${ }^{23,25,35}$ showed no significant difference in all-cause mortality between the urate oxidase and control groups. However, pooled results of three $\mathrm{CCTs}^{23,25,34}$ showed a significantly lower mortality due to TLS in the group that received Uricozyme or rasburicase compared with the group that received allopurinol, ${ }^{17}$ which could be interpreted as level 3 evidence in favor of urate oxidase in children. Lopez-Olivo et al attempted to perform a metaanalysis evaluating mortality among other outcomes, but due to intertrial heterogeneity in terms of outcomes reported, were unable to do so. ${ }^{16}$ They did, however, combine reported mortality events from nine different studies that resulted in a pooled estimated death rate of 0.03 ( $95 \%$ confidence interval $0.01-0.05$, standard error $0.32[0.20-0.45]) .{ }^{16}$ However, in the absence of a comparison with a pooled estimated death rate for allopurinol-treated controls, this information does not allow us to conclude that mortality is reduced by rasburicase in adults.

\section{Safety/tolerability}

Almost all of the studies we found reported rates of adverse events and evaluated the data for safety (Table 4). There was consistency among all trials in terms of adverse events, and the safety of rasburicase is supported by level 1 evidence. The most common conclusion was that, except for those with glucose-6phosphate dehydrogenase (G6PD) deficiency, in whom rasburicase can cause hemolysis and potentially methemoglobinemia, there are very few side effects. ${ }^{16,31,40,41}$ Precautions can be taken to prevent the potentially dangerous side effects of hemolysis and methemoglobinemia by screening those of African or Mediterranean descent for G6PD deficiency. Rasburicase should not be given to those with known G6PD deficiency. ${ }^{2}$

The 2013 systematic review of studies in adult patients only reported total adverse events of $2.6 \%$ (95\% confidence interval 1.7-3.8) when combining all studies. ${ }^{16}$ However, the Cochrane database systematic review of the pediatric literature ${ }^{17}$ noted a significantly higher frequency of adverse events in participants who received urate oxidase compared with those who received allopurinol, based on pooled results from three CCTs, one of which used Uricozyme rather than rasburicase. ${ }^{23-25}$ Malaguarnera et al list all of the adverse effects from studies published between 2001 and 2009, with the most common being neutropenic fever, sepsis, respiratory distress, mucositis, nausea, vomiting, headache, and diarrhea. ${ }^{40}$ Clearly, many of these may not be attributable to rasburicase. Hypersensitivity reactions needing to be addressed or closely monitored included skin rashes $(1.4 \%)$ and urticaria or bronchospasm $(<1 \%) .^{40}$

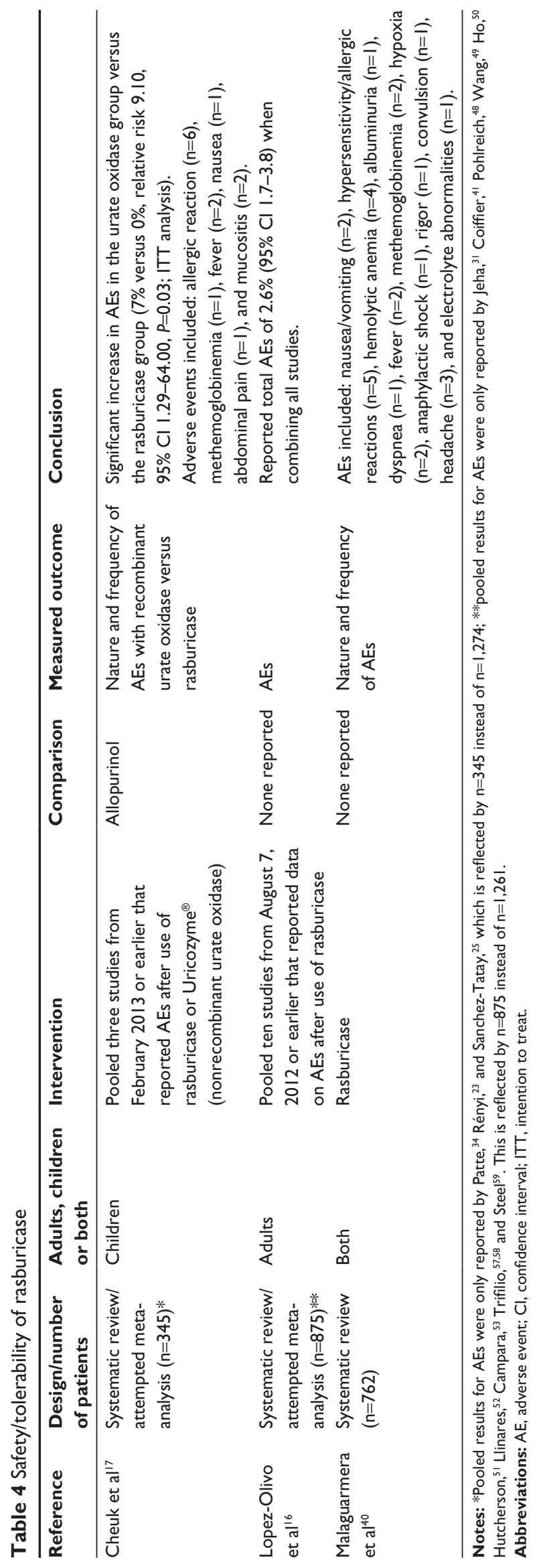




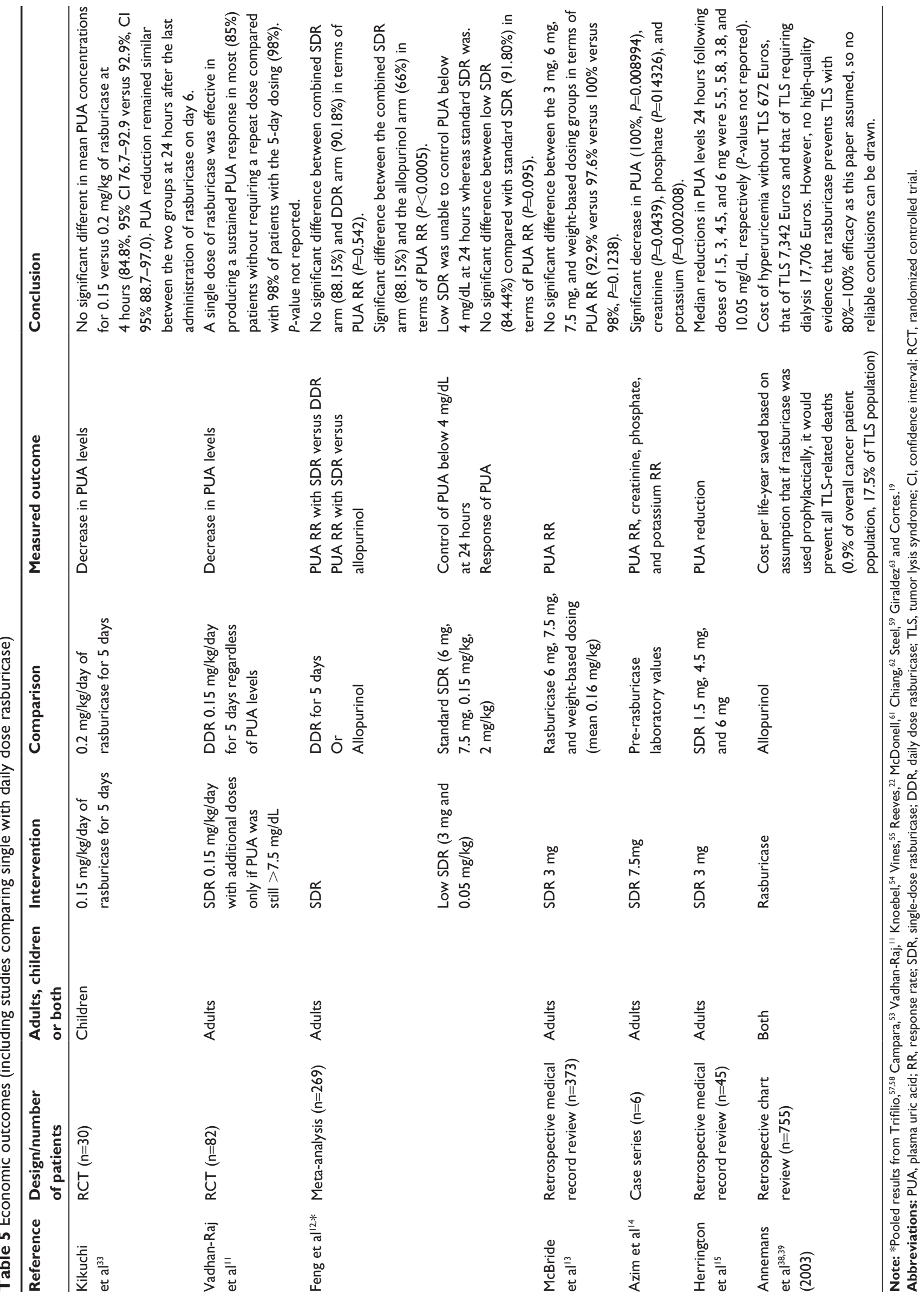




\section{Economic evidence Effective dose}

Most of the trials in our study involved a reduced dose or duration of administration of rasburicase (Table 5). Amongst the "primary evidence" articles, the main objective of 12 retrospective and nine prospective studies was to evaluate the effects of dose reduction. Our criteria for inclusion were the highest levels of evidence, which included a meta-analysis reported in 2013 as well as the only two RCTs on dose reduction. ${ }^{11,12,33}$ We also included all studies published after the meta-analysis; these consisted of two retrospective medical record reviews and a case series. ${ }^{13-15}$ All of these studies were consistent in their results that single-dose rasburicase (SDR) is effective.

The FDA approved rasburicase at a dose of $0.2 \mathrm{mg} / \mathrm{kg}$ daily for 5 days; however, there is level 1 evidence that smaller doses and/or shorter durations are just as effective in preventing TLS and its sequelae. ${ }^{12-15}$ A RCT comparing rasburicase $0.2 \mathrm{mg} /$ $\mathrm{kg} /$ day with rasburicase $0.15 \mathrm{mg} / \mathrm{kg} /$ day for 5 days in pediatric patients with newly diagnosed hematologic malignancies at high risk for TLS found no significant differences in PUA lowering, all-cause mortality, or adverse events. ${ }^{33}$ Another RCT compared a single $0.15 \mathrm{mg} / \mathrm{kg}$ dose of rasburicase with five daily doses in adult patients at risk for TLS ${ }^{11}$ and found that SDR was effective in producing a sustained PUA response in most $(85 \%)$ patients, with only a few high-risk patients requiring a second dose. Feng et al performed a meta-analysis combining ten studies (eight retrospective and two prospective) on SDR and found that there was no difference between daily dose rasburicase $(\mathrm{n}=132)$ and SDR $(\mathrm{n}=269)$ in terms of pooled PUA RR $(90.18 \%$ versus $88.15 \%, P=0.542) .{ }^{12}$ To determine the appropriate dose of SDR in adult cancer patients at high risk of TLS, they divided patients in the selected SDR studies into a pooled lower-dose group ( $3 \mathrm{mg}$ and $0.05 \mathrm{mg} / \mathrm{kg}, \mathrm{n}=91$ ) and a pooled standard-dose group $(6 \mathrm{mg}, 7.5 \mathrm{mg}, 0.15 \mathrm{mg} / \mathrm{kg}, 0.2 \mathrm{mg} / \mathrm{kg}, \mathrm{n}=155)$. The pooled lower-dose SDR group failed to control the PUA level below $4 \mathrm{mg} / \mathrm{dL}$ at 24 hours, whereas the pooled standard-dose SDR group maintained a PUA level below $4 \mathrm{mg} / \mathrm{dL}$ at 24, 48, and 72 hours. In addition, the PUA RR in the standard-dose SDR group $(91.80 \%, \mathrm{n}=155)$ was higher than in the lower-dose SDR group $(84.44 \%, \mathrm{n}=91)$, although the difference was not statistically significant $(P=0.095)$. Furthermore, standard-dose SDR was associated with substantial cost savings compared with daily dose rasburicase. ${ }^{12}$ Three other studies comparing doses have been completed since the publication of this meta-analysis, all of which supported SDR. ${ }^{13-15}$ McBride et al evaluated SDR 3 $\mathrm{mg}(\mathrm{n}=38), 6 \mathrm{mg}(\mathrm{n}=99)$, and $7.5 \mathrm{mg}(\mathrm{n}=43)$, as well as weightbased dosing (mean $0.16 \mathrm{mg} / \mathrm{kg}, \mathrm{n}=193$ ), in a retrospective medical record review-based study. ${ }^{13}$ Unfortunately, the $3 \mathrm{mg}$ group had a lower baseline median PUA level than the other groups..$^{13}$ Although there was no significant difference in PUA normalization between the groups at 24 hours $(92.9 \%$ versus $97.6 \%$ versus $100.0 \%$ versus $98.0 \%$ in the $3 \mathrm{mg}, 6 \mathrm{mg}, 7.5 \mathrm{mg}$, and weight-based dosing groups, respectively, $P=0.1238$ ), the $6 \mathrm{mg}$ dose resulted in lower sustained PUA levels. ${ }^{13}$ In another retrospective review of 45 adults receiving fixed, low-dose rasburicase, $58 \%$ of patients received $3 \mathrm{mg} .{ }^{15}$ The median reductions in PUA levels 24 hours following doses of $1.5,3,4.5$, and $6 \mathrm{mg}$ were $5.5,5.8,3.8$, and $10.05 \mathrm{mg} / \mathrm{dL}$, respectively. ${ }^{15}$ While the lowest effective dose of rasburicase is not known with certainty, the $6 \mathrm{mg}$ single dose is the most widely used, and there is thus level 1 evidence that SDR is as effective as weight-based daily dosing in controlling PUA and is cheaper.

There is overwhelming evidence that rasburicase is effective in rapidly lowering PUA levels. ${ }^{16}$ Some evidence also supports a decrease in the incidence of LTLS, CTLS, AKI, need for RRT, ICU admissions, and hospital/ICU LOS when rasburicase is used to decrease PUA levels in patients at high risk for TLS. However, the evidence supporting these clinical benefits is more limited than the evidence supporting a rapid reduction in PUA. Therefore, there still remains significant debate with regard to the appropriate clinical indications for administration of rasburicase. Given that rasburicase has minimal side effects, ${ }^{16,17,40}$ the chief limiting factor is cost. ${ }^{36-39}$ Recent research has focused on determining how to administer rasburicase in the most cost-effective manner without sacrificing clinical benefit. To date, two major avenues have been explored to optimize the cost/benefit ratio for this drug. These two broad strategies involve finding the lowest effective dose and duration of rasburicase administration, thus minimizing drug costs, and determining which patients will obtain the most benefit. The ultimate goal is to appropriately risk-stratify patients so as to use the drug judiciously, such that patient outcomes may be optimized in the most cost-effective manner. While the most appropriate clinical indication for the use of rasburicase has to be individualized, attempts have been made by experts to provide some guidance for clinicians in determining the risk of TLS in a given patient. ${ }^{6,7}$ Even though rasburicase is now routinely used in patients with TLS, debate persists as to whether rasburicase confers benefits beyond lowering PUA levels. ${ }^{17} \mathrm{~A}$ close look at the evidence demonstrates that rasburicase may, in fact, impact the clinical course of high-risk patients beyond simply lowering the PUA level.

\section{Conclusion and future directions}

A plethora of host-related, treatment-related, and diseaserelated factors influence the risk and severity of TLS., ${ }^{2,6,7}$ 
Virtually any class of effective anticancer therapy can precipitate TLS, and solid tumors are no exception. ${ }^{42,43}$ Indeed, outcomes of TLS occurring in the latter setting may be worse due to delayed recognition resulting from a lower index of suspicion. ${ }^{3}$ Additionally, some studies have shown that hypophosphatemia at presentation, as well as elevated lactate dehydrogenase, disseminated intravascular coagulation, and comorbidities such as hypertension and severe hyperuricemia, place patients at higher risk for worse outcomes, even with the use of rasburicase. ${ }^{16,27,28,44}$ One study found that patients with a lower PUA response to rasburicase had worse outcomes. ${ }^{44}$ Clearly, there is a need to continually refine our risk stratification strategies so as to best prevent or manage TLS and use this expensive agent in the most cost-effective manner. This might require a multidisciplinary approach, and given that the kidney is the organ most often affected adversely in TLS, collaboration between oncologists and nephrologists is key. In this regard, the emergence of a new field, that of "onconephrology", is a welcome development. ${ }^{45}$

Rasburicase is a safe drug (clear evidence) which probably improves outcomes in patients at high risk for TLS (clear evidence that it reduces uric acid, substantial evidence of reduction in LTLS/CLTS and AKI/need for RRT, moderate evidence of reduced ICU LOS, and limited evidence of decreased TLS mortality, see Clinical impact summary). There is a marked paucity of high-quality evidence linking rasburicase to improvements in "hard outcomes" such as need for RRT and mortality, and its use is largely based on its dramatic effectiveness in lowering PUA levels, which has been widely used in trials as a surrogate for CTLS and AKI. The major disadvantage of the drug is its high cost, a problem that has been mitigated to some extent by the demonstration that use of single, fixed doses does not compromise efficacy. Improved risk stratification of patients for TLS will be critical to optimizing the use of this unquestionably active agent. Finally, RCTs demonstrating clinical benefit beyond lowering of PUA levels will help position this drug best in the supportive therapy armamentarium for patients with cancer.

\section{Disclosure}

$\mathrm{PB}$ reports receiving honoraria from Sanofi US, the manufacturer of rasburicase (Elitek ${ }^{\circledR}$ ) as compensation for advisory board participation. The other authors report no conflicts of interest relevant to this work.

\section{References}

1. Cairo MS, Bishop M. Tumour lysis syndrome: new therapeutic strategies and classification. Br J Haematol. 2004;127(1):3-11.
2. Howard SC, Jones DP, Pui CH. The tumor lysis syndrome. $N$ Engl J Med. 2011;364(19):1844-1854.

3. Coiffier B. Acute tumor lysis syndrome - a rare complication in the treatment of solid tumors. Onkologie. 2010;33(10):498-499.

4. Darmon M, Guichard I, Vincent F, Schlemmer B, Azoulay E. Prognostic significance of acute renal injury in acute tumor lysis syndrome. Leuk Lymphoma. 2010;51(2):221-227.

5. Shimada M, Johnson RJ, May WS, et al. A novel role for uric acid in acute kidney injury associated with tumour lysis syndrome. Nephrol Dial Transplant. 2009;24(10):2960-2964.

6. Coiffier B, Altman A, Pui CH, Younes A, Cairo MS. Guidelines for the management of pediatric and adult tumor lysis syndrome: an evidencebased review. J Clin Oncol. 2008;26(16):2767-2778.

7. Cairo MS, Coiffier B, Reiter A, Younes A, Panel TE. Recommendations for the evaluation of risk and prophylaxis of tumour lysis syndrome (TLS) in adults and children with malignant diseases: an expert TLS panel consensus. Br J Haematol. 2010;149(4):578-586.

8. Zaidi SZ, Aljurf M. Is rasburicase needed for prevention of tumor lysis syndrome during treatment of less aggressive hematolymphoid malignancies? J Clin Oncol. 2004;22(16):3430-3431.

9. Feusner JH, Ritchey AK, Cohn SL, Billett AL. Management of tumor lysis syndrome: need for evidence-based guidelines. J Clin Oncol. 2008;26(34):5657-5658.

10. Darmon M, Guichard I, Vincent F. Rasburicase and tumor lysis syndrome: lower dosage, consideration of indications, and hyperhydration. J Clin Oncol. 2011;29(3):e67-e68.

11. Vadhan-Raj S, Fayad LE, Fanale MA, et al. A randomized trial of a single-dose rasburicase versus five-daily doses in patients at risk for tumor lysis syndrome. Ann Oncol. 2012;23(6):1640-1645.

12. Feng X, Dong K, Pham D, Pence S, Inciardi J, Bhutada NS. Efficacy and cost of single-dose rasburicase in prevention and treatment of adult tumour lysis syndrome: a meta-analysis. J Clin Pharm Ther. 2013;38(4): 301-308.

13. McBride A, Lathon SC, Boehmer L, Augustin KM, Butler SK, Westervelt P. Comparative evaluation of single fixed dosing and weight-based dosing of rasburicase for tumor lysis syndrome. Pharmacotherapy. 2013;33(3):295-303.

14. Azim HA, Bahr SA, Kamal NS, et al. One for the road! A study to assess the efficacy of single low-dose regimen of rasburicase in controlling hyperuricaemia in patients with tumour lysis syndrome due to haematological malignancies. Ecancermedicalscience. 2013;7:378.

15. Herrington JD, Dinh BC. Fixed, low-dose rasburicase for the treatment or prevention of hyperuricemia in adult oncology patients. $J$ Oncol Pharm Pract. February 18, 2014. [Epub ahead of print.]

16. Lopez-Olivo MA, Pratt G, Palla SL, Salahudeen A. Rasburicase in tumor lysis syndrome of the adult: a systematic review and meta-analysis. Am J Kidney Dis. 2013;62(3):481-492.

17. Cheuk DK, Chiang AK, Chan GC, Ha SY. Urate oxidase for the prevention and treatment of tumour lysis syndrome in children with cancer. Cochrane Database Syst Rev. 2014;8:CD006945.

18. Goldman SC, Holcenberg JS, Finklestein JZ, et al. A randomized comparison between rasburicase and allopurinol in children with lymphoma or leukemia at high risk for tumor lysis. Blood. 2001;97(10): 2998-3003.

19. Cortes J, Moore JO, Maziarz RT, et al. Control of plasma uric acid in adults at risk for tumor lysis syndrome: efficacy and safety of rasburicase alone and rasburicase followed by allopurinol compared with allopurinol alone - results of a multicenter phase III study. J Clin Oncol. 2010;28(27):4207-4213.

20. Galardy PJ, Hochberg J, Perkins SL, Harrison L, Goldman S, Cairo MS. Rasburicase in the prevention of laboratory/clinical tumour lysis syndrome in children with advanced mature B-NHL: a Children's Oncology Group Report. Br J Haematol. 2013;163(3): 365-372.

21. Ishizawa K, Ogura M, Hamaguchi M, et al. Safety and efficacy of rasburicase (SR29142) in a Japanese Phase II study. Cancer Sci. 2009;100(2):357-362. 
22. Reeves DJ, Bestul DJ. Evaluation of a single fixed dose of rasburicase $7.5 \mathrm{mg}$ for the treatment of hyperuricemia in adults with cancer. Pharmacotherapy. 2008;28(6):685-690.

23. Rényi I, Bárdi E, Udvardi E, et al. Prevention and treatment of hyperuricemia with rasburicase in children with leukemia and non-Hodgkin's lymphoma. Pathol Oncol Res. 2007;13(1):57-62.

24. Pui CH, Relling MV, Lascombes F, et al. Urate oxidase in prevention and treatment of hyperuricemia associated with lymphoid malignancies. Leukemia. 1997;11(11):1813-1816.

25. Tatay VS, Castilla JD, Ponce JM, Hurtado JM, Cantero E, Abril ML. [Rasburicase versus allopurinol in the treatment of hyperuricaemia in tumour lysis syndrome]. An Pediatr (Barc). 2010;72(2):103-110. Spanish.

26. Cairo MS, Gerrard M, Sposto R, et al. Results of a randomized international study of high-risk central nervous system B non-Hodgkin lymphoma and B acute lymphoblastic leukemia in children and adolescents. Blood. 2007;109(7):2736-2743.

27. Ahn YH, Kang HJ, Shin HY, Ahn HS, Choi Y, Kang HG. Tumour lysis syndrome in children: experience of last decade. Hematol Oncol. 2011;29(4):196-201.

28. Darmon M, Vincent F, Camous L, et al. Tumour lysis syndrome and acute kidney injury in high-risk haematology patients in the rasburicase era. A prospective multicentre study from the Groupe de Recherche en Réanimation Respiratoire et Onco-Hématologique. Br J Haematol. 2013;162(4):489-497.

29. Cairo MS. Results of a randomized international study of high-risk central nervous system B non-Hodgkin lymphoma and B acute lymphoblastic leukemia in children and adolescents. Blood. 2007;109(7): 2736-2743.

30. Pannucci CJ, Wilkins EG. Identifying and avoiding bias in research. Plast Reconstr Surg. 2010;126(2):619-625.

31. Jeha S, Kantarjian H, Irwin D, et al. Efficacy and safety of rasburicase, a recombinant urate oxidase (Elitek), in the management of malignancyassociated hyperuricemia in pediatric and adult patients: final results of a multicenter compassionate use trial. Leukemia. 2005;19(1): 34-38.

32. Hande KR, Garrow GC.Acute tumor lysis syndrome in patients with highgrade non-Hodgkin's lymphoma. Am J Med. 1993;94(2):133-139.

33. Kikuchi A, Kigasawa H, Tsurusawa M, et al. A study of rasburicase for the management of hyperuricemia in pediatric patients with newly diagnosed hematologic malignancies at high risk for tumor lysis syndrome. Int J Hematol. 2009;90(4):492-500.

34. Patte C, Sakiroglu C, Ansoborlo S, et al. Urate-oxidase in the prevention and treatment of metabolic complications in patients with B-cell lymphoma and leukemia, treated in the Société Française d'Oncologie Pédiatrique LMB89 protocol. Ann Oncol. 2002;13(5):789-795.

35. Wössmann W, Schrappe M, Meyer U, Zimmermann M, Reiter A. Incidence of tumor lysis syndrome in children with advanced stage Burkitt's lymphoma/leukemia before and after introduction of prophylactic use of urate oxidase. Ann Hematol. 2003;82(3): $160-165$

36. Eaddy M, Seal B, Tangirala K, Davies EH, O’Day K. Economic implications of rasburicase treatment in adult patients with tumour lysis syndrome. Appl Health Econ Health Policy. 2012;10(6):431-440

37. Eaddy M, Seal B, Tangirala M, Davies EH, O’Day K. Economic comparison of rasburicase and allopurinol for treatment of tumor lysis syndrome in pediatric patients. Am J Health Syst Pharm. 2010;67(24): 2110-2114.

38. Annemans L, Moeremans K, Lamotte M, et al. Incidence, medical resource utilisation and costs of hyperuricemia and tumour lysis syndrome in patients with acute leukaemia and non-Hodgkin's lymphoma in four European countries. Leuk Lymphoma. 2003;44(1):77-83.

39. Annemans L, Moeremans K, Lamotte M, et al. Pan-European multicentre economic evaluation of recombinant urate oxidase (rasburicase) in prevention and treatment of hyperuricaemia and tumour lysis syndrome in haematological cancer patients. Support Care Cancer. 2003;11(4):249-257.
40. Malaguarnera G, Giordano M, Malaguarnera M. Rasburicase for the treatment of tumor lysis in hematological malignancies. Expert Rev Hematol. 2012;5(1):27-38.

41. Coiffier B, Mounier N, Bologna S, et al. Efficacy and safety of rasburicase (recombinant urate oxidase) for the prevention and treatment of hyperuricemia during induction chemotherapy of aggressive non-Hodgkin's lymphoma: results of the GRAAL1 (Groupe d'Etude des Lymphomes de 1'Adulte Trial on Rasburicase Activity in Adult Lymphoma) study. J Clin Oncol. 2003;21(23):4402-4406.

42. Bose P, Qubaiah O. A review of tumour lysis syndrome with targeted therapies and the role of rasburicase. J Clin Pharm Ther. 2011;36(3): 299-326.

43. Mott FE, Esana A, Chakmakjian C, Herrington JD. Tumor lysis syndrome in solid tumors. Support Cancer Ther. 2005;2(3): 188-191.

44. Canet E, Cheminant M, Zafrani L, et al. Plasma uric acid response to rasburicase: early marker for acute kidney injury in tumor lysis syndrome? Leuk Lymphoma. 2014;55(10):2362-2367.

45. Finkel KW, Howard SC. Onco-nephrology: an invitation to a new field. J Clin Oncol. 2014;32(22):2389-2390.

46. Lascombes F, Sommelet D, Gebhard F. High efficacy of recombinant urate oxidase in prevention of renal failure related to tumor lysis syndrome (TLS). 1998;92(10):237B.

47. Bosly A, Sonet A, Pinkerton CR, et al. Rasburicase (recombinant urate oxidase) for the management of hyperuricemia in patients with cancer: report of an international compassionate use study. Cancer. 2003;98(5):1048-1054.

48. Pohlreich D, Soukup P, Kouba M, al. Reduced-dose regimen of rasburicase with parallel allopurinol in the management of malignancyassociated hyperuricemia and tumor lysis syndrome. Bone Marrow Transplant. 2003;31:S223-S224.

49. Wang LY, Shih LY, Chang H, et al. Recombinant urate oxidase (rasburicase) for the prevention and treatment of tumor lysis syndrome in patients with hematologic malignancies. Acta Haematol. 2006; 115(1-2):35-38.

50. Ho VQ, Wetzstein GA, Patterson SG, Bradbury R. Abbreviated rasburicase dosing for the prevention and treatment of hyperuricemia in adults at risk for tumor lysis syndrome. Support Cancer Ther. 2006;3(3):178-182.

51. Hutcherson DA, Gammon DC, Bhatt MS, Faneuf M. Reduced-dose rasburicase in the treatment of adults with hyperuricemia associated with malignancy. Pharmacotherapy. 2006;26(2):242-247.

52. Llinares F, Burgos A, Fernández P, Villarrubia B, Ferrandis P, Ordovás JP. [Analysis and protocolization of rasburicase use in patients with hematologic neoplasms]. Farm Hosp. 2006;30(2):92-98.

53. Campara M, Shord SS, Haaf CM. Single-dose rasburicase for tumour lysis syndrome in adults: weight-based approach. J Clin Pharm Ther. 2009;34(2):207-213.

54. Knoebel RW, Lo M, Crank CW. Evaluation of a low, weight-based dose of rasburicase in adult patients for the treatment or prophylaxis of tumor lysis syndrome. J Oncol Pharm Pract. 2011;17(3):147-154.

55. Vines AN, Shanholtz CB, Thompson JL. Fixed-dose rasburicase $6 \mathrm{mg}$ for hyperuricemia and tumor lysis syndrome in high-risk cancer patients. Ann Pharmacother. 2010;44(10):1529-1537.

56. Yim B, Navaleza A, Haidau A, al e. Single $4.5 \mathrm{mg}$ dose of rasburicase for tumor lysis syndrome in adults. 2010;116(21):741-742.

57. Trifilio SM, Pi J, Zook J, et al. Effectiveness of a single 3-mg rasburicase dose for the management of hyperuricemia in patients with hematological malignancies. Bone Marrow Transplant. 2011;46(6):800-805.

58. Trifilio S, Gordon L, Singhal S, et al. Reduced-dose rasburicase (recombinant xanthine oxidase) in adult cancer patients with hyperuricemia. Bone Marrow Transplant. 2006;37(11):997-1001.

59. Steel S, Coutsouvelis J, McKendrick J. Single dose rasburicase in tumor lysis: one hospital's experience. Clin Oncol. 2008;4(1):18-20.

60. Chow V, Lee K. Single fixed dose versus weight-based dosing of rasburicase for the treatment of hyperuricemia associated with tumor lysis syndrome in adults with hematologic malignancies. 2009;7(5):196-197. 
61. McDonnell AM, Lenz KL, Frei-Lahr DA, Hayslip J, Hall PD. Singledose rasburicase $6 \mathrm{mg}$ in the management of tumor lysis syndrome in adults. Pharmacotherapy. 2006;26(6):806-812.

62. Chiang J, Chan A, Lian T, et al. Management of tumor lysis syndrome with a single fixed dose of rasburicase in Asian lymphoma patients: a case series and literature review. Asia Pac J Clin Oncol. 2011;7(4):351-356.
63. Giraldez M, Puto K. A single, fixed dose of rasburicase (6 mg maximum) for treatment of tumor lysis syndrome in adults. Eur J Haematol. 2010;85(2):177-179.

\section{Publish your work in this journal}

Core Evidence is an international, peer-reviewed open-access journal evaluating the evidence underlying the potential place in therapy of drugs throughout their development lifecycle from preclinical to postlaunch. The focus of each review is to evaluate the case for a new drug or class in outcome terms in specific indications and patient groups.
The manuscript management system is completely online and includes a very quick and fair peer-review system, which is all easy to use. Visit http://www.dovepress.com/testimonials.php to read real quotes from published authors. 